\title{
AVALIAÇÃO TEMPORAL DA FLORÍSTICA ARBÓREA DE UMA FLORESTA SECUNDÁRIA NO MUNICÍPIO DE VIÇOSA, MINAS GERAIS ${ }^{1}$
}

\author{
Crodoaldo Telmo da Silva², Geraldo Gonçalves dos Reis ${ }^{3}$, Maria das Graças Ferreira Reis ${ }^{3}$, Elias Silva ${ }^{3}$, \\ Rogério de Araújo Chaves ${ }^{4}$
}

\begin{abstract}
RESUMO - Avaliou-se a composição florística, por um período de nove anos, em um fragmento de Floresta Estacional Semidecidual Secundária localizada no Município de Viçosa, Minas Gerais, com o objetivo de se avaliar a dinâmica da vegetação arbórea. A coleta dos dados dessa vegetação, com diâmetro à altura do peito (DAP a 1,3 m) igual ou superior a $5 \mathrm{~cm}$, foi realizada em 10 locais, em parcelas permanentes. As espécies amostradas foram identificadas, sempre que possível, em níveis de família, gênero e espécie. Em nove anos de estudo foram amostradas 161 espécies, 114 gêneros e 48 famílias, sendo as famílias Leguminosae, Lauraceae, Euphorbiaceae, Myrtaceae, Flacourtiaceae e Meliaceae, as que tiveram a maior riqueza de espécies. O índice de diversidade de Shannon-Weaver variou de 2,26 a 3,65, quando analisado para cada local, e de 4,22 a 4,26 para o fragmento como um todo, ao longo de nove anos. O grupo ecológico que mais se destacou foi o das secundárias iniciais, seguido pelas secundárias tardias ou pelas pioneiras, a depender da abertura do dossel do local estudado, indicando que o fragmento se encontrava em estádio médio de sucessão. A variabilidade na composição florística em função dos locais estudados e na proporção de espécies em cada grupo ecológico era resultante das variações na intensidade da ação antrópica, bem como das condições fisiográficas, em especial exposição e declividade do terreno. Planos de manejo para essas florestas devem levar em conta essa variabilidade de condições ambientais.
\end{abstract}

Palavras-chave: Composição florística, diversidade, Floresta Estacional Semidecidual.

\section{FLORISTIC OF ADULT TREES IN A SECONDARY FOREST IN VIÇOSA, MG, SOUTHEASTERN BRAZIL}

\begin{abstract}
The floristic composition of a seasonal semi-deciduous secondary forest was evaluated every three years during a nine year period in a fragment of 196 ha located in Viçosa, MG (20 45' Latitude South, $42^{\circ} 55^{\prime}$ Longitude West and altitude of $689,7 \mathrm{~m}$ ), Southeastern Brazil, in the domain of the Atlantic Forest. A total of 161 tree species, 114 genera and 48 botanical families were recognized considering trees with DBH equal or greater than $5 \mathrm{~cm}$. The families Leguminosae, Lauraceae, Euphorbiaceae, Myrtaceae, Flacourtiaceae and Meliaceae exhibited the greatest species richness and most of them were initial secondary species. ShannonWeaver diversity index varied from 2.26 to 3.65 when the analysis was made as a function of sites. It was observed a great variability in species composition among sites due to physiographic variation. The higher proportion of initial secondary species indicated that the forest fragment studied is in an intermediate stage of succession.
\end{abstract}

Key words: Floristic composition, diversity, semi-deciduous seasonal forest.

\footnotetext{
${ }^{1}$ Recebido para publicação em 16.3.2003 e aceito para publicação em 08.6.2004.

2 Mestrado em Ciência Florestal da Universidade Federal de Viçosa, Rua Benevenuto Saraiva, 271, Nova Era, 36570-000 Viçosa, Minas Gerais, Brasil.<ms35063@mail.ufv.br>.

${ }^{3}$ Professores do Departamento de Engenharia Florestal da Universidade Federal de Viçosa, 36571-000 Viçosa, Minas Gerais, Brasil, <greis@ufv.br>,<mgfreis@ufv.br>, <eshamir@ufv.br>.Bolsistas CNPq.

${ }^{4}$ Mestrando em Ciência Florestal da Universidade Federal de Viçosa, 36570-000 Viçosa, Minas Gerais, Brasil.

Apoio: FAPEMIG, CNPq e CAPES.
} 


\section{INTRODUÇÃO}

As intervenções antrópicas em florestas nativas, como desmatamento para construção de centros urbanos, formação de pastagem, atividades agrícolas e exploração madeireira, além da freqüente ocorrência de incêndios, têm comprometido a integridade desses ecossistemas. Dentre os processos impactantes, destacam-se a redução da área com cobertura vegetal e, principalmente, a fragmentação da vegetação, com sua conseqüente degradação, em razão da diminuição contínua do tamanho do fragmento e de seu isolamento (PEREIRA, 1999).

Para entender o processo de sucessão das comunidades vegetais e a influência das modificações do ambiente sobre a vegetação, há necessidade de estudos ao longo de um período de tempo para subsidiar a elaboração de planos de manejo para conservar e preservar a vegetação remanescente. Nesses estudos, em geral, analisam-se a composição florística e o comportamento das espécies em comunidades vegetais (MARANGON et al., 2003). No entanto, pouco se sabe sobre a interação entre espécies e o meio em que vivem, o que dificulta o manejo adequado dos remanescentes florestais.

No sentido de entender as mudanças florísticas que podem ocorrer ao longo do tempo, este trabalho objetivou estudar a dinâmica da composição florística da vegetação arbórea adulta, no período de nove anos, em uma Floresta Estacional Semidecidual Secundária, visando auxiliar a elaboração de planos de manejo para esses ambientes.

\section{MATERIAL E MÉTODOS}

O estudo foi desenvolvido em um fragmento florestal de 196 ha na Estação de Pesquisa, Treinamento e Educação Ambiental (EPTEA) da Universidade Federal de Viçosa, localizada a $5 \mathrm{~km}$ da cidade de Viçosa, MG (2045’ latitude sul e 4255' longitude oeste, a uma altitude média de $689,7 \mathrm{~m}$ ). O relevo é montanhoso, a precipitação média anual da região é de $1.221 \mathrm{~mm}$ - concentrada entre os meses de outubro a março - e a temperatura média anual é de $19^{\circ} \mathrm{C}$ (VIANELLO eALVES, 1991). A formação florestal da região é classificada como Floresta Estacional Semidecidual Montana (VELOSO et al., 1991) e a vegetação do fragmento florestal estudado é considerada Floresta Secundária Residual com vários estádios serais, formando um mosaico florestal, em função de diferentes épocas e graus de intervenção (LEAL FILHO, 1992).

Para o estudo e coleta de dados da dinâmica da composição florística da vegetação arbórea, foram utilizadas parcelas permanentes (Figura 1) em 10 sítios com diferenças quanto à exposição do terreno, declividade e abertura do dossel, alocadas por Volpato (1994), com dimensões de 20 x $60 \mathrm{~m}\left(1.200 \mathrm{~m}^{2}\right)$, subdividida em seis subparcelas de 10 x $20 \mathrm{~m}\left(200 \mathrm{~m}^{2}\right)$. O mapa da cobertura vegetal apresentado na Figura 1 refere-se ao ano de 1963, ou seja, à época da instalação das parcelas permanentes em 1992, todas as áreas estudadas eram de floresta secundária. As caracterizações ambientais dos locais estudados, de acordo com Fernandes (1998) e Pezzopane (2001), estão apresentadas no Quadro 1. A cada três anos, de 1992 a 2001, foram coletados dados de altura total e diâmetro à altura do peito (DAP a 1,3 m) de indivíduos da vegetação arbórea que apresentavam DAP igual ou superior a $5 \mathrm{~cm}$, após serem marcados e numerados com plaquetas de alumínio galvanizado. Em 1992, foi realizado o primeiro levantamento, e em 1995, 1998 e 2001 foram levantadas e identificadas as árvores que ingressaram na classe de DAP superior ou igual a $5 \mathrm{~cm}$, em cada subparcela.

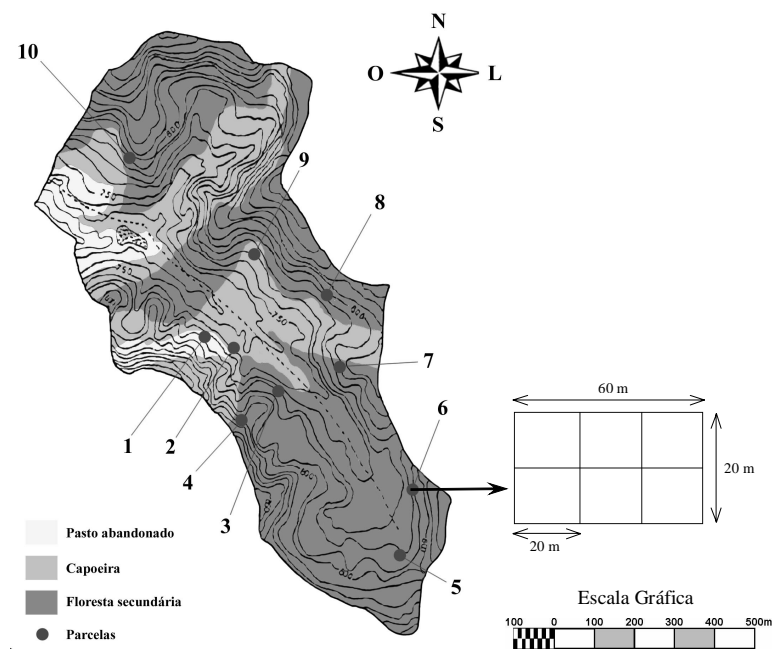

Figura 1 - Localização das parcelas permanentes na Estação de Pesquisa, Treinamento e Educação Ambiental no Município de Viçosa, Minas Gerais (Mapa da cobertura vegetal, em 1963, conforme Leal Filho, 1992).

Figure 1-Distribution of the permanent plots in the forest fragment studied, in Viçosa, Minas Gerais, Brazil (Vegetation cover map in 1963 based on Leal Filho, 1992). 
Quadro 1 - Caracterização da declividade (D), exposição (Exp), posição topográfica (PT), abertura do dossel (AD), transmissividade da RFA (t) e índice de área foliar (IAF) dos 10 locais estudados na Estação de Pesquisa, Treinamento e Educação Ambiental, Município de Viçosa, MG

Table 1 -Slope (D), aspect (Exp), topographic position (PT), canopy opening (AD), photosynthetic active radiation transmissivity (t) and leaf area index (IAF) of the ten sites studied in a secondary semi-deciduous seasonal forest fragment, in the domain of the Atlantic Forest, in Viçosa, MG, Brazil

\begin{tabular}{|c|c|c|c|c|c|c|}
\hline Local & $\mathrm{D}(\%)^{1}$ & Exp. $^{1}$ & $\mathrm{PT}^{1}$ & $\mathrm{AD}^{1}$ & $\mathrm{t}(\%)^{2}$ & $\mathrm{IAF}^{2}$ \\
\hline 1 & 40 & $\mathrm{NE}$ & Terço superior & muito aberto & 8,9 & 3,6 \\
\hline 2 & 21 & $\mathrm{NE}$ & Meia encosta & Mediamente fechado & 6,0 & 4,5 \\
\hline 3 & 43 & $\mathrm{NE}$ & Terço inferior & Fechado & 2,7 & 4,9 \\
\hline 4 & 80 & $\mathrm{NE}$ & Meia encosta & Aberto & 9,3 & 3,6 \\
\hline 5 & 3 & & Baixada & Fechado & 1,7 & 5,2 \\
\hline 6 & 51 & SO & Terço inferior & Fechado & 1,8 & 5,0 \\
\hline 7 & 45 & $\mathrm{SO}$ & Meia encosta & Fechado & 1,6 & 5,2 \\
\hline 8 & 20 & $\mathrm{SO}$ & Meia encosta & Aberto & 3,7 & 4,2 \\
\hline 9 & 14 & SO & Terço inferior & Muito aberto & 2,8 & 5,1 \\
\hline 10 & 45 & SO & Terço superior & Mediamente fechado & 2,5 & 4,3 \\
\hline
\end{tabular}

NE - Nordeste e SO - Sudoeste.

Fonte: ${ }^{1}$ Fernandes (1998), a representa a condição em que se encontrava o dossel da floresta em 1995; e ${ }^{2}$ Pezzopane (2001), valores médios de medições realizadas em maio, agosto e novembro de 1999 e março de 2000.

As espécies encontradas foram identificadas, sempre que possível, em níveis de família, gênero e espécie. Quando necessário, foi coletado material botânico para auxiliar a identificação dos indivíduos amostrados por profissionais conhecedores da vegetação local e através de consultas em catálogos do herbário do Setor de Dendrologia do Departamento de Engenharia Florestal e do Setor de Botânica do Departamento de Biologia Vegetal da Universidade Federal de Viçosa. A família das leguminosae foi dividida em três subfamílias (Caesalpinioideae, Faboideae e Mimosoideae) e para as outras famílias foi adotado o Sistema de Classificação de Cronquist (CRONQUIST, 1988). A nomenclatura de binômios científicos e respectivos autores foram consultados, confirmados e atualizados através do site $<$ www.ipni.org/ipni/query_ipni.html>, onde a fonte de dados foi o Index Kewensis (acessado em 11/12/2002).

A diversidade florística foi estimada através do índice Shannon-Weaver (H’), por ser o mais utilizado nos estudos de florística. Utilizou-se o teste "t”, de Magurram (1987), citado por Vidal et al. (1998), a 5\% de probabilidade, para averiguar se existem diferenças significativas entre os índices ShannonWeaver (H') de um levantamento para o outro em cada local e para o fragmento como um todo, tendo sido feita a comparação aos pares (1992 com 1995, 1992 com 1998, 1992 com 2001, 1995 com 1998, 1995 com 2001 e 1998 com 2001). Também, foi realizada a classificação sucessional das espécies amostradas, com base em dados de campo do presente estudo e através de consulta aos trabalhos realizados na região (FERNANDES, 1998; ALMEIDA JÚNIOR, 1999; PEZZOPANE, 2001; LOUZADA, 2002), com o objetivo de caracterizar o estádio sucessional em que essa floresta secundária se encontrava.

\section{RESULTADOS E DISCUSSÃO}

Nos levantamentos florísticos realizados na área de estudo de 1992 a 2001 (nove anos) foram amostrados 161 espécies, 114 gêneros e 48 famílias, sendo 22 espécies identificadas apenas em nível de gênero e três em nível de família (Quadro 2). As famílias Combretaceae e Ochnaceae foram coletadas a partir do levantamento de 1995, e Ulmaceae surgiu em 1998. Em 2001, as famílias Clethraceae e Elaeocarpaceae, amostradas nos estudos anteriores, desapareceram. As famílias com apenas uma espécie foram Araliaceae, Boraginaceae, Chysobalanaceae, Clethraceae, Combretaceae, Cunoniaceae, Elaeocarpaceae, Erythroxylaceae, Labiatae, Lacistemaceae, Myristicaceae, Myrsinaceae, Ochnaceae, Rhamnaceae, Rosaceae, Solanaceae, Tiliaceae, Ulmaceae e Verbenaceae, representando $11,08 \%$ das espécies amostradas durante nove anos de estudo.

R. Árvore, Viçosa-MG, v.28, n.3, p. 429-441, 2004

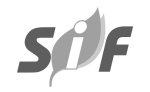


Quadro 2 - Lista de espécies arbóreas amostradas em 10 locais, nos anos de 1992, 1995, 1998 e 2001, em uma floresta secundária, na Estação de Pesquisa, Treinamento e Educação Ambiental, no Município de Viçosa, Minas Gerais, em ordem alfabética de famílias, gêneros e espécies e sua classificação ecológica (GE), como pioneiras (P), secundárias iniciais (SI) e secundárias tardias (ST)

Table 2 - Floristic composition of adult tree species, with its equivalent ecological group (pioneer-PI, initial secondarySI and late secondary-ST) sampled in 1992, 1995, 1998 and 2001, in a secondary semi-deciduous seasonal forest fragment, domain of the Atlantic Forest, in Viçosa, MG, Brazil

\begin{tabular}{|c|c|c|c|c|c|c|c|}
\hline Família & Espécie/Gênero & Nome vulgar & GE & 1992 & 1995 & 1998 & 2001 \\
\hline \multirow[t]{2}{*}{ ANACARDIACEAE } & Tapirira guianensis Aubl. & Tapirira & SI & + & + & + & + \\
\hline & Tapirira obtusa (Benth.) Mitch. & Mamoneira-preta & SI & + & + & + & - \\
\hline \multirow[t]{5}{*}{ ANNONACEAE } & Annona cacans Warm. & Jaca-do-mato & SI & + & + & + & + \\
\hline & Guatteria nigrescens Mart. & Pindaíba & SI & + & + & + & + \\
\hline & Rollinia silvatica Mart. & Araticum & SI & + & + & + & + \\
\hline & Xylopia brasiliensis Spreng & Asa-de-barata & SI & + & + & + & + \\
\hline & Xylopia sericea A. St.-Hil. & Pimenteira & $\mathrm{P}$ & + & + & + & + \\
\hline \multirow[t]{4}{*}{ APOCYNACEAE } & $\begin{array}{l}\text { Aspidosperma olivaceum } \\
\text { Müll. Arg. }\end{array}$ & Guatambu & SI & + & + & + & + \\
\hline & Aspidosperma sp. & Peroba-mirim & ST & + & + & + & + \\
\hline & $\begin{array}{l}\text { Himatanthus phagedaenicus } \\
\text { (Mart.) Woodson }\end{array}$ & Cana-de-macaco & SI & + & + & + & + \\
\hline & Peschiera fuchsiaefolia Miers & Esperta-brava & SI & + & + & + & + \\
\hline \multirow[t]{2}{*}{ ARALIACEAE } & $\begin{array}{l}\text { Didymopanax morototoni } \\
\text { (Aubl.) }\end{array}$ & & SI & + & + & + & + \\
\hline & Maguire, Steyerm. \& Frodin & Morototó & & & & & \\
\hline \multirow[t]{5}{*}{ BIGNONIACEAE } & Cybistax antisyphilitica Mart. & Ipê-de-pasto & $\mathrm{P}$ & + & + & + & + \\
\hline & Jacaranda sp. & Caroba & SI & + & + & + & + \\
\hline & $\begin{array}{l}\text { Sparattosperma leucanthum } \\
\text { K. Schum. }\end{array}$ & Cinco-folhas-brancas & SI & + & + & + & + \\
\hline & $\begin{array}{l}\text { Tabebuia chrysotricha } \\
\text { (Mart. ex DC.) Standl. }\end{array}$ & Ipê-mulato & SI & - & + & + & + \\
\hline & $\begin{array}{l}\text { Zeyheria tuberculosa } \\
\text { Bureau ex Verl. }\end{array}$ & Ipê-preto & SI & + & + & + & + \\
\hline \multirow[t]{2}{*}{ BOMBACACEAE } & $\begin{array}{l}\text { Eriotheca candolleana } \\
\text { (K. Schum.) A. Robyns }\end{array}$ & Mandioquinha & SI & + & + & + & + \\
\hline & $\begin{array}{l}\text { Pseudobombax longiflorum } \\
\text { (Mart. \& Zucc.) A. Robyns }\end{array}$ & Imbiruçu & SI & + & + & + & + \\
\hline BORAGINACEAE & Cordia sericicalyx A. DC. & Poleiro-de-morcego & SI & + & + & + & + \\
\hline \multirow[t]{2}{*}{ BURSERACEAE } & Protium warmingianum March. & Amescla & ST & + & + & + & + \\
\hline & Trattinickia ferruginea Kuhlm. & Cedrinho & SI & + & + & + & + \\
\hline \multirow[t]{2}{*}{ CECROPIACEAE } & Cecropia glaziovii Snethl. & Embaúba-vermelha & $\mathrm{P}$ & + & + & + & + \\
\hline & Cecropia hololeuca Miq. & Embaúba-branca & $\mathrm{P}$ & + & + & + & + \\
\hline CHRYSOBALANACEAE & $\begin{array}{l}\text { Hirtella hebeclada Moric. } \\
\text { ex A. DC. }\end{array}$ & Hirtela & ST & + & + & + & + \\
\hline CLETHRACEAE & Clethra sp. & Caituá-vermelho & SI & + & + & + & - \\
\hline COMBRETACEAE & Terminalia sp. & Osso-de-frango & ST & - & + & + & + \\
\hline \multirow[t]{2}{*}{ COMPOSITAE } & Piptocarpha macropoda Baker. & Pau-de-fumo & $\mathrm{P}$ & + & + & + & + \\
\hline & Vernonia diffusa Less. & Pau-de-fumo & $\mathrm{P}$ & + & + & + & + \\
\hline CUNONIACEAE & Lamanonia ternata Vell. & Cinco-folhas-vermelhas & SI & + & + & + & + \\
\hline ELAEOCARPACEAE & Sloanea sp. & - & ST & + & + & + & - \\
\hline ERYTHROXYLACEAE & $\begin{array}{l}\text { Erythroxylum pelleterianum } \\
\text { A. St.-Hil }\end{array}$ & Sessenta-e-um & SI & + & + & + & + \\
\hline \multirow[t]{8}{*}{ EUPHORBIACEAE } & $\begin{array}{l}\text { Alchornea glandulosa } \\
\text { Poepp. \& Endl. }\end{array}$ & Casca-doce & $\mathrm{P}$ & + & + & + & + \\
\hline & Alchornea sp. & Tapiciri & SI & + & + & + & + \\
\hline & Alchornea triplinervia Müll. Arg. & Casca-doce-miúda & SI & + & + & + & - \\
\hline & Croton floribundus Spreng. & Capixingui & $\mathrm{P}$ & + & + & + & + \\
\hline & Hieronyma alchorneoides Fr. All. & Liquerana & SI & + & + & + & + \\
\hline & Mabea fistulifera Mart. & Canudo-de-pito & $\mathrm{P}$ & + & + & + & + \\
\hline & Maprounea guianensis Aubl. & Vaquinha-branca & SI & + & + & + & + \\
\hline & Sapium glandulatum (Vell.) Pax & Leiteiro & SI & + & + & + & + \\
\hline \multirow[t]{2}{*}{ FLACOURTIACEAE } & Carpotroche brasiliensis Endl. & Sapucainha & SI & + & + & + & + \\
\hline & Casearia aculeata Jacq. & Espeto-branco & SI & + & + & + & + \\
\hline
\end{tabular}


Quadro 2, cont.

Table 2, cont.

\begin{tabular}{|c|c|c|c|c|c|c|c|}
\hline Família & Espécie/Gênero & Nome vulgar & GE & 1992 & 1995 & 1998 & 2001 \\
\hline \multirow[t]{6}{*}{ FLACOURTIACEAE } & Casearia gossypiosperma Briq. & Espeto-vidro & SI & + & + & + & + \\
\hline & Casearia sp. & - & SI & + & + & + & + \\
\hline & Casearia sp. 1 & Espeto & SI & + & + & + & + \\
\hline & Casearia sp. 2 & Espeto-miúdo & SI & + & + & + & + \\
\hline & Casearia sylvestris $\mathrm{Sw}$. & Café-do-mato & SI & + & + & + & + \\
\hline & Xylosma prockia (Turcz.) Turcz. & Roseta & SI & + & + & + & + \\
\hline \multirow[t]{4}{*}{ GUTTIFERAE } & $\begin{array}{l}\text { Rheedia gardneriana } \\
\text { Planch. \& Triana }\end{array}$ & Bacupari & SI & + & + & + & + \\
\hline & Guttiferae 1 & - & SI & - & - & + & - \\
\hline & Tovomita glazioviana Engl. & Tovomita & SI & + & + & + & - \\
\hline & Vismia guianensis (Aubl.) Choisy & Ruão & $\mathrm{P}$ & + & + & + & + \\
\hline \multirow[t]{2}{*}{ ICACINACEAE } & Citronella paniculata (Mart.)Howard & Canela-branca & ST & + & + & + & + \\
\hline & Villaresia megaphylla Miers & Peroba-branca & SI & + & + & + & + \\
\hline LABIATAE & $\begin{array}{l}\text { Hyptidendron asperrimum } \\
\text { (Spreng.) Harley }\end{array}$ & São-josé, Maria-chora & SI & + & + & + & + \\
\hline \multirow{12}{*}{$\begin{array}{l}\text { LACISTEMACEAE } \\
\text { LAURACEAE }\end{array}$} & Lacistema pubescens Mart. & Espeto-vermelho & SI & + & + & + & + \\
\hline & Aniba firmula $\mathrm{Mez}$ & & ST & - & - & + & + \\
\hline & $\begin{array}{l}\text { Endlicheria paniculata } \\
\text { (Spreng.) J. F. Macbr. }\end{array}$ & Canela-preta & ST & + & + & + & + \\
\hline & Lauraceae 1 & - & SI & + & + & + & + \\
\hline & Nectandra reticulata $\mathrm{Mez}$ & Canela-cabeluda & SI & - & + & + & + \\
\hline & Nectandra rigida Nees & Canela-amarela & SI & + & + & + & + \\
\hline & Nectandra saligna Nees & Canela-parda & SI & + & + & + & + \\
\hline & Ocotea corymbosa $\mathrm{Mez}$ & Canela-miúda & ST & + & + & + & + \\
\hline & Ocotea laxa Mez & Canela-prego & SI & + & + & + & + \\
\hline & Ocotea odorifera (Vell.) Rohwer & Canela-sassafrás & ST & + & + & + & + \\
\hline & Ocotea pubescens Mez & Canela-peludinha & ST & + & + & + & + \\
\hline & $\begin{array}{l}\text { Phyllostemonodaphne geminiflora } \\
\text { (Mez) Kosterm. }\end{array}$ & Canela-coquinho & SI & + & + & + & + \\
\hline \multirow[t]{2}{*}{ LECYTHIDACEAE } & Cariniana estrellensis Kuntze & Jequitibá-rosa & ST & + & + & + & + \\
\hline & \multicolumn{6}{|c|}{ LEGUMINOSAE } & + \\
\hline \multirow{9}{*}{ CAESALPINIOIDEAE } & Apuleia leiocarpa J. F. Macbr. & Garapa & SI & + & + & + & + \\
\hline & Bauhinia forficata Link & Unha-de-vaca & $\mathrm{P}$ & + & + & + & + \\
\hline & Copaifera langsdorffii Desf. & Copaíba & ST & + & + & + & + \\
\hline & Melanoxylon brauna Schott & Braúna-parda & ST & + & + & + & - \\
\hline & Sclerolobium denudatum Vogel & Mamoneira-branca & ST & + & + & + & + \\
\hline & Senna macranthera (DC. ex Collad & d.) & $\mathrm{P}$ & + & + & + & + \\
\hline & Irwin \& Barneby & Fédegoso & & & & & \\
\hline & $\begin{array}{l}\text { Senna multijuga (Rich.) } \\
\text { Irwin \& Barneby }\end{array}$ & Farinha-seca & $\mathrm{P}$ & + & + & + & + \\
\hline & Swartzia myrtifolia Sm. & Jasmim, Laranjinha & $\mathrm{ST}$ & + & + & + & + \\
\hline \multicolumn{8}{|l|}{ LEGUMINOSAE } \\
\hline \multirow[t]{9}{*}{ PAPILLIONOIDEAE } & Andira fraxinifolia Benth. & Angelim-pedra & SI & + & + & + & - \\
\hline & Andira sp. & Angelim & ST & + & + & + & + \\
\hline & Dalbergia nigra Fr. All. ex Benth. & Jacarandá-da-bahia & SI & + & + & + & + \\
\hline & Erythrina sp. & Eritrina & SI & + & + & + & + \\
\hline & Lonchocarpus sp. & Lonchocarpus & SI & + & + & + & + \\
\hline & $\begin{array}{l}\text { Machaerium nyctitans } \\
\text { (Vell.) Benth. }\end{array}$ & Bico-de-pato & SI & + & + & + & + \\
\hline & Machaerium stipitatum Vogel & Feijão-cru & SI & + & + & + & + \\
\hline & Machaerium triste Vogel & Sangue-de-burro & SI & + & + & + & + \\
\hline & Platymiscium pubescens Micheli & Tamboril-da-mata & ST & + & + & + & + \\
\hline \multirow{8}{*}{$\begin{array}{l}\text { LEGUMINOSAE } \\
\text { MIMOSOIDEAE }\end{array}$} & & & & & & & \\
\hline & Acacia glomerosa Benth. & Angico-preto & SI & + & + & + & + \\
\hline & Anadenanthera peregrina Speg. & Angico-vermelho & SI & + & + & + & + \\
\hline & Inga capitata Desv. & - & SI & - & + & - & - \\
\hline & Inga edulis Mart. & Ingá & SI & + & + & + & + \\
\hline & Inga marginata Willd. & Ingá-ferro & SI & + & + & + & + \\
\hline & Inga sp. & Ingá-miúdo & SI & + & + & + & + \\
\hline & $\begin{array}{l}\text { Piptadenia gonoacantha } \\
\text { (Vell.) Benth. }\end{array}$ & Jacaré & SI & + & + & + & + \\
\hline
\end{tabular}
(Vell.) Benth. 
Quadro 2, cont

Table 2, cont. .

\begin{tabular}{|c|c|c|c|c|c|c|c|}
\hline Família & Espécie/Gênero & Nome vulgar & GE & 1992 & 1995 & 1998 & 2001 \\
\hline \multirow{3}{*}{$\begin{array}{l}\text { LEGUMINOSAE } \\
\text { MIMOSOIDEAE }\end{array}$} & & & & & & & \\
\hline & $\begin{array}{l}\text { Pseudopiptadenia contorta (DC.) } \\
\text { G. P. Lewis \& M. P. Lima }\end{array}$ & Angico-branco & SI & + & + & + & + \\
\hline & $\begin{array}{l}\text { Stryphnodendron guianense } \\
\text { Benth. }\end{array}$ & Barbatimão & SI & + & + & + & + \\
\hline \multirow[t]{5}{*}{ MELASTOMATACEAE } & Miconia albo-rufescens Naudin & Quaresmão & $\mathrm{P}$ & + & + & + & + \\
\hline & Miconia cinnamomifolia Triana & Quaresminha-branca & $\mathrm{P}$ & + & + & + & + \\
\hline & Miconia pusilliflora Triana & Murici-branco & SI & - & - & + & + \\
\hline & Miconia sp. & Quaresminha & $\mathrm{P}$ & - & - & + & + \\
\hline & Tibouchina granulosa Cogn. & Quaresma-roxa & SI & + & + & + & + \\
\hline \multirow[t]{7}{*}{ MELIACEAE } & Cabralea canjerana (Vell.) Mart. & Canjerana & ST & + & + & + & + \\
\hline & Guarea guidonia (L.) Sleumer & Cura-madre & SI & + & + & + & + \\
\hline & Guarea kunthiana A. Juss. & Canjerana-vermelha & ST & - & + & + & + \\
\hline & Guarea macrophylla Vahl & - & ST & + & + & + & + \\
\hline & Trichilia catigua A. Juss. & Caituá-aroeira/miúdo & ST & + & + & + & + \\
\hline & Trichilia lepidota Sw. & - & ST & + & + & + & + \\
\hline & Trichilia pallida $\mathrm{Sw}$. & Trichilia-branca & ST & - & - & - & + \\
\hline \multirow[t]{2}{*}{ MONIMIACEAE } & Siparuna arianeae V. Pereira & Folha-santa 2 & SI & + & + & + & + \\
\hline & Siparuna guianensis Aubl. & Folha-santa & SI & + & + & + & + \\
\hline \multirow[t]{6}{*}{ MORACEAE } & $\begin{array}{l}\text { Brosimum guianense } \\
\text { Huber ex Ducke }\end{array}$ & Vaquinha-vermelha & ST & + & + & + & + \\
\hline & Ficus insipida Willd. & Gameleira & SI & + & + & + & + \\
\hline & Ficus mexiae Standl. & Gameleira-mexiae & SI & + & + & + & + \\
\hline & Ficus sp. & Gameleira-ficus & SI & + & + & + & + \\
\hline & $\begin{array}{l}\text { Maclura tinctoria } \\
\text { D. Don ex Steud. }\end{array}$ & Tajuba & SI & + & + & + & + \\
\hline & $\begin{array}{l}\text { Sorocea bonplandii (Baill.) } \\
\text { W. C. Burger, Lanj. \& Boer }\end{array}$ & Folha-de-serra & SI & + & + & + & + \\
\hline MYRISTICACEAE & $\begin{array}{l}\text { Virola oleifera (Schott) } \\
\text { A. C. Sm. }\end{array}$ & Bicuíba & SI & + & + & + & + \\
\hline MYRSINACEAE & Rapanea ferruginea $\mathrm{Mez}$ & Canela-azeitona & $\mathrm{P}$ & + & + & + & + \\
\hline \multirow[t]{9}{*}{ MYRTACEAE } & Calyptranthes sp. & Canela-rapadura & ST & + & + & + & + \\
\hline & Eugenia brasiliensis Lam. & Jambo-branco & SI & + & + & + & + \\
\hline & Eugenia cf. cerasiflora Miq. & Caituá & SI & + & + & + & + \\
\hline & Eugenia leptoclada Berg & Jabuticaba-do-mato & SI & + & + & + & + \\
\hline & Myrcia fallax DC. & Jambo-vermelho & SI & + & + & + & + \\
\hline & Myrcia sp. & Jambo & SI & + & + & + & + \\
\hline & Myrciaria sp. & - & SI & + & + & + & + \\
\hline & Myrtaceae 1 & - & SI & - & - & - & + \\
\hline & Psidium guajava L. & Goiabeira & ST & + & + & + & + \\
\hline NYCTAGINACEAE & Guapira opposita (Vell.) Reitz & Folha-santa & SI & + & + & + & + \\
\hline OCHNACEAE & Ouratea polygyna Engl. & Ouratea & SI & - & + & + & + \\
\hline \multirow[t]{3}{*}{ PALMAE } & $\begin{array}{l}\text { Astrocaryum aculeatissimum } \\
\text { (Schott) Burret }\end{array}$ & Brejaúba & ST & + & + & + & + \\
\hline & Euterpe edulis Mart. & Palmito-doce & ST & + & + & + & + \\
\hline & $\begin{array}{l}\text { Syagrus romanzoffiana } \\
\text { (Cham.) Glassm. }\end{array}$ & Coquinho-de-baba & SI & + & + & + & + \\
\hline RHAMNACEAE & Colubrina glandulosa Perkins & Sobrasil & SI & + & + & + & + \\
\hline ROSACEAE & Prunus sellowii Koehne & Pessegueiro-do-mato & ST & + & + & + & + \\
\hline \multirow{6}{*}{ RUBIACEAE } & Amaioua guianensis Aubl. & Azeitona-preta & SI & + & + & + & + \\
\hline & $\begin{array}{l}\text { Coutarea hexandra } \\
\text { (Jacq.) K. Schum. }\end{array}$ & Guiné-do-mato & SI & + & + & + & + \\
\hline & $\begin{array}{l}\text { Guettarda viburnoides } \\
\text { Cham. \& Schltdl. }\end{array}$ & Castanheira-do-mato & SI & + & + & + & + \\
\hline & Ladenbergia hexandra Klotzsch & Pau-de-colher & ST & + & + & + & + \\
\hline & $\begin{array}{l}\text { Psychotria sessilis } \\
\text { (Vell.) Müll. Arg. }\end{array}$ & Cafezinho & SI & + & + & + & + \\
\hline & Randia armata DC. & Bosta-de-pato & SI & + & + & + & + \\
\hline \multirow{3}{*}{ RUTACEAE } & Citrus sp. & Limoeiro & SI & + & + & + & + \\
\hline & Dictyoloma vandellianum A. Juss. & Brauninha & SI & + & + & + & + \\
\hline & Hortia arborea Engl. & Paratudo & ST & + & + & + & + \\
\hline
\end{tabular}


Quadro 2, cont.

Table 2, cont..

\begin{tabular}{|c|c|c|c|c|c|c|c|}
\hline Família & Espécie/Gênero & Nome vulgar & GE & 1992 & 1995 & 1998 & 2001 \\
\hline RUTACEAE & Zanthoxylum rhoifolium Lam. & Mama-de-porca & ST & + & + & + & + \\
\hline \multirow[t]{5}{*}{ SAPINDACEAE } & $\begin{array}{l}\text { Allophylus edulis } \\
\text { Radlk. ex Warm. }\end{array}$ & Três-folhas-vermelhas & ST & + & + & + & + \\
\hline & Allophylus sericeus Radlk. & Três-folhas-brancas & ST & + & + & + & + \\
\hline & Cupania sp. & Camboatá & ST & + & + & + & + \\
\hline & Matayba elaeagnoides Radlk. & Camboatá-branco & SI & + & + & + & + \\
\hline & Matayba juglandifolia Engl. & Camboatá-miúdo & SI & + & + & + & + \\
\hline \multirow[t]{2}{*}{ SAPOTACEAE } & Chrysophyllum flexuosum Mart. & Falso-araticum & ST & + & + & + & + \\
\hline & Pouteria sp. & Gumixa & SI & + & + & + & + \\
\hline \multirow[t]{2}{*}{ SIMAROUBACEAE } & Picramnia glazioviana Engl. & Uva-do-mato & ST & + & + & + & + \\
\hline & Picramnia regnelli Engl. & - & ST & - & + & + & + \\
\hline \multirow[t]{6}{*}{ SOLANACEAE } & $\begin{array}{l}\text { Solanum argenteum } \\
\text { Dunal. ex Poir. }\end{array}$ & Mercurinho & $\mathrm{P}$ & + & + & + & + \\
\hline & Solanum cernuum Vell. & Braço-de-mono & $\mathrm{P}$ & + & + & + & + \\
\hline & $\begin{array}{l}\text { Solanum granuloso-leprosum } \\
\text { Dunal }\end{array}$ & Capoeira-branca & $\mathrm{P}$ & - & + & - & - \\
\hline & Solanum leucodendron Sendt. & Pau-mercúrio & $\mathrm{P}$ & - & + & + & + \\
\hline & Solanum sp.1 & Mercurinho-branco & $\mathrm{P}$ & + & + & + & + \\
\hline & Solanum sp.2 & Mercurinho-preto & $\mathrm{P}$ & + & + & + & - \\
\hline TILIACEAE & Luehea grandiflora Mart. \& Zucc. & Açoita-cavalo & SI & + & + & + & + \\
\hline ULMACEAE & Trema micrantha Blume & Crindiúva & $\mathrm{P}$ & - & - & + & + \\
\hline VERBENACEAE & Vitex sellowiana Cham. & Maria-preta & SI & + & + & + & + \\
\hline
\end{tabular}

Legenda: Presença (+) e Ausência (-); GE = Grupo ecológico

As famílias que se destacaram em relação ao número de espécies, no período de nove anos, foram Leguminosae, Lauraceae, Euphorbiaceae, Myrtaceae, Flacourtiaceae e Meliaceae. Souza et al. (2002), estudando a dinâmica da composição florística de uma floresta ombrófila densa secundária, no Estado do Espírito Santo, por um período de oito anos, e Campos (2002), pesquisando um fragmento de Floresta Estacional Semidecidual Montana, em Viçosa, Minas Gerais, também encontraram as mesmas famílias entre as de maior riqueza de espécies, embora, em ordem de importância diferente, possivelmente devido ao histórico de perturbação e ao tamanho do fragmento. Leitão Filho (1987) reuniu diversos trabalhos em florestas semideciduais e observou que, entre as principais famílias, estavam presentes Leguminosae, Meliaceae, Euphorbiaceae, Lauraceae e Myrtaceae.

Em outros trabalhos, também desenvolvidos na região de Viçosa, Minas Gerais, a família Leguminosae apresentou maior riqueza de espécies (SILVA et al., 2000; LOPEZ et al., 2002; PAULA et al., 2002; MARANGON et al., 2003). Segundo Silva (2002), a capacidade de fixar nitrôgenio mostrada por indivíduos de algumas espécies dessa família pode ser a estratégia de vida que tem conferido uma riqueza de espécies a essa familía, considerando-se a baixa fer- tilidade natural dos solos da região, principalmente em encostas e topo de morros. Santos e Ribeiro (1975), citados por Martins (1979), explicaram a grande presença de indivíduos da família Leguminosae nas campinas amazônicas (sobre solo de textura arenosa), devido à presença de nódulos radiculares agindo na retenção e transferência de nitrogênio.

Em 2001, 23\% das espécies apresentaram apenas um indivíduo amostrado em toda a área de estudo, conforme a lista a seguir: Acacia glomerosa, Aniba firmula, Aspidosperma sp., Calyptranthes sp., Citronella paniculata, Citrus sp., Endlicheria paniculata, Eugenia leptoclada, Ficus insipida, Ficus mexiae, Ficus sp., Rheedia gardneriana, Guarea kunthiana, Himatanthus phagedaenicus, Inga sp., Machaerium triste, Maclura tinctoria, Matayba juglandifolia, Miconia alborufescens, Miconia sp., Myrtaceae 1, Nectandra reticulata, Picramnia glazioviana, Pouteria sp., Rapanea ferruginea, Solanum cernuum, Solanum sp.1, Stryphnodendron guianense, Swartzia myrtifolia, Tabebuia chrysotricha, Terminalia sp., Tibouchina granulosa, Trema micrantha, Trichilia pallida e Xylopia brasiliensis. Entre essas espécies, algumas se apresentaram com um único indivíduo em todos os levantamentos, sendo elas: Calyptranthes sp., Citrus sp., Ficus insipida, Ficus mexiae, Ficus sp., Himatanthus 
phagedaenicus, Machaerium triste, Matayba juglandifolia, Picramnia glazioviana, Pouteria sp., Solanum sp.1, Swartzia myrtifolia, Terminalia sp. e Xylopia brasiliensis. Elas podem estar correndo algun risco de extinção, principalmente Ficus insipida, Ficus mexiae e Xylopia brasiliensis, que não têm apresentado regeneração natural na área de estudo (HIGUCHI, 2003).

Paula et al. (2002) relataram que uma espécie pode ser extinta, sem necessáriamente haver redução drástica de sua densidade populacional seja drasticamente reduzida, ressaltando-se que a mudança no número de indivíduos de sexos diferentes e a disponibilidade de polinizadores podem comprometer a população de plantas dióicas na comunidade. Por isso, é preciso preservar e conservar os remanescentes florestais, podendo ser necessário, em determinadas circunstâncias, interferir no ecossistema para manter sua diversidade biológica.

No primeiro ano de levantamento (1992) havia 146 espécies, e em 1995 surgiram as seguintes espécies, classificadas nos grupos ecológicos de pioneiras (P), secundárias iniciais (SI) e secundárias tardias (ST): Guarea kunthiana (ST), Inga capitata (SI), Nectandra reticulata (SI), Ouratea polygyna (SI), Picrania regnelli (ST), Solanum granuloso-leprosum (P), Tabebuia chrysotricha (SI) e Terminalia sp. (ST), não havendo o desaparecimento de espécies neste período, totalizando 154 espécies. Após seis anos (1998), surgiram Aniba firmula (ST), Guttiferae 1 (SI), Miconia pusilliflora (P), Miconia sp. (P) e Trema micrantha (P), e nesse período desapareceram Inga capitata (SI) e Solanum granuloso-leprosum (P), quando comparado com o levantamento de 1995, quando foi amostrado um total de 157 espécies. Em 2001, surgiram as espécies Trichilia pallida (ST) e uma espécie da família Myrtaceae, denominada aqui Myrtaceae 1 (SI), em relação ao ano de 1998, mas saíram Alchornea tripinervia (SI), Andira fraxinifolia (SI), Clethra sp. (SI), espécie denominada aqui Guttiferae 1 (SI), Melanoxylum brauna (ST), Sloanea sp. (ST), Solanum sp. 2 (P), Tapirira obtusa (SI) e Tovomita glazioviana (SI), totalizando 150 espécies em 2001. Em razão dessas mudanças na listagem de espécies, houve também variação no número de gêneros e famílias amostradas (Quadro 2). Tais resultados indicam haver elevada dinâmica na população da vegetação arbórea ao longo de nove anos de estudo desse fragmento.

No ano de 2001 havia 52 espécies que ocorriam apenas em um local. Dessas espécies, somente Astrocaryum aculeatissimum, Cariniane legalis, Casearia sp., Colubrina glandulosa, Guarea kuntiana, Hirtella hebeclada, Lonchocarpus sp., Picramnia regnelli, Psycotria sessilis, Tapirira guianensis e Zeyheria tuberculosa podem ser consideradas exclusivas de determinado sítio, por apresentar grande número de indivíduos em um sítio específico e ausência ou reduzido número de indivíduos em outros sítios nessas áreas (Quadro 3). Nectantra rigida e Siparuna guianensis não têm preferência por um sítio, pois ocorrem em todos os locais estudados.

Quadro 3 - Lista de espécies arbóreas amostradas (x) em 10 locais, no ano de 2001, em uma floresta secundária, na Estação de Pesquisa, Treinamento e Educação Ambiental, no Município de Viçosa, Minas Gerais

Table 3 -Floristic composition of adult tree species, sampled (x) in ten sites, in the year 2001, in a secondary semi-deciduous seasonal forest fragment, domain of the Atlantic Forest, in Viçosa, MG, Brazil

\begin{tabular}{|c|c|c|c|c|c|c|c|c|c|}
\hline \multirow[t]{2}{*}{ Espécies } & \multicolumn{9}{|c|}{ Local } \\
\hline & 1 & 2 & 3 & 4 & 5 & 6 & 8 & 9 & 10 \\
\hline Acacia glomerosa & - & - & - & - & - & - & $\bar{x}$ & - & - \\
\hline Alchornea glandulosa & - & - & - & - & $\mathrm{X}$ & $\mathrm{x}$ & - & - & - \\
\hline Alchornea sp. & - & - & - & $\mathrm{x}$ & - & - & - & - & $\mathrm{x}$ \\
\hline Allophylus edulis & - & $\mathrm{x}$ & - & - & $\mathrm{x}$ & $\mathrm{x}$ & $\mathrm{x}$ & $\mathrm{x}$ & $\mathrm{x}$ \\
\hline Allophylus sericeus & - & - & - & - & $\mathrm{x}$ & - & $\mathrm{x}$ & - & - \\
\hline Amaioua guianensis & - & - & $\mathrm{x}$ & $\mathrm{x}$ & - & - & - & - & $\mathrm{x}$ \\
\hline Anadenanthera peregrina & - & $\mathrm{x}$ & - & - & $\mathrm{x}$ & $\mathrm{x}$ & - & $\mathrm{x}$ & - \\
\hline Andira sp. & - & - & $\mathrm{x}$ & - & $\mathrm{X}$ & - & - & - & $\mathrm{x}$ \\
\hline Aniba firmula & - & - & & - & $\mathrm{x}$ & - & - & - & - \\
\hline Annona cacans & - & $\mathrm{x}$ & $\mathrm{x}$ & - & - & - & - & $\mathrm{x}$ & - \\
\hline Apuleia leiocarpa & - & $\mathrm{x}$ & $\mathrm{x}$ & $\mathrm{x}$ & - & $\mathrm{x}$ & $\mathrm{x}$ & - & $\mathrm{x}$ \\
\hline Aspidosperma olivaceum & - & - & - & $\mathrm{x}$ & - & - & - & - & $\mathrm{x}$ \\
\hline Aspidosperma sp. & - & - & - & - & - & $\mathrm{x}$ & - & - & - \\
\hline Astrocaryum & - & - & - & - & - & - & $\mathrm{x}$ & - & - \\
\hline aculeatissimum & & & & & & & & & \\
\hline Bauhinia forficata & $\mathrm{x}$ & $\mathrm{x}$ & $\mathrm{x}$ & - & $\mathrm{x}$ & $\mathrm{x}$ & $\mathrm{x}$ & $\mathrm{x}$ & - \\
\hline Brosimum guianense & - & - & $\mathrm{x}$ & $\mathrm{x}$ & - & - & - & - & $\mathrm{x}$ \\
\hline Cabralea canjerana & - & - & - & - & $\mathrm{x}$ & - & $\mathrm{x}$ & - & $\mathrm{x}$ \\
\hline Calyptranthes sp. & - & - & - & - & $\mathrm{x}$ & - & - & - & - \\
\hline Cariniana estrellensis & - & - & $\mathrm{x}$ & - & - & $\mathrm{X}$ & - & - & - \\
\hline Cariniana legalis & - & - & - & - & - & $\mathrm{x}$ & - & - & - \\
\hline Carpotroche brasiliensis & - & - & $\mathrm{x}$ & $\mathrm{x}$ & $\mathrm{x}$ & $\mathrm{x}$ & - & - & $\mathrm{x}$ \\
\hline Casearia aculeata & - & - & $\mathrm{x}$ & $\mathrm{x}$ & - & $\mathrm{x}$ & - & $\mathrm{x}$ & $\mathrm{x}$ \\
\hline Casearia gossypiospe & - & $\mathrm{x}$ & $\mathrm{x}$ & $\mathrm{x}$ & - & $\mathrm{x}$ & - & $\mathrm{x}$ & $\mathrm{x}$ \\
\hline Casearia sp. & - & - & $\mathrm{x}$ & - & - & - & - & - & - \\
\hline Casearia sp. 1 & - & - & - & $\mathrm{x}$ & - & - & $\mathrm{x}$ & - & - \\
\hline Casearia sp. 2 & - & - & - & $\mathrm{x}$ & - & - & - & - & $\mathrm{x}$ \\
\hline Casearia sylvestris & - & - & - & - & $\mathrm{x}$ & $\mathrm{x}$ & - & - & - \\
\hline Cecropia glaziovii & $\mathrm{x}$ & - & - & - & - & - & - & $\mathrm{x}$ & - \\
\hline Cecropia hololeuca & - & $\mathrm{x}$ & - & - & - & - & $\mathrm{x}$ & $\mathrm{x}$ & - \\
\hline Chrysophyllum flexuosum & - & - & - & - & $\mathrm{x}$ & $\mathrm{x}$ & - & - & - \\
\hline Citronella paniculata & - & - & $\mathrm{x}$ & - & - & - & - & - & - \\
\hline Citrus sp. & & . & - & $\underline{x}$ & - & & - & - & - \\
\hline
\end{tabular}


Quadro 3, cont.

Table 3, cont.

\begin{tabular}{|c|c|c|c|c|c|c|c|c|c|}
\hline \multirow[t]{2}{*}{ Espécies } & \multicolumn{9}{|c|}{ Local } \\
\hline & 1 & 2 & 3 & 4 & 5 & 6 & 8 & 9 & 10 \\
\hline olubrina glandulosa & - & - & $\mathrm{x}$ & - & - & 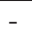 & - & 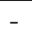 & 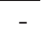 \\
\hline Copaifera langsdorffii & - & - & - & $\mathrm{x}$ & $\mathrm{x}$ & - & - & 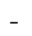 & - \\
\hline Cordia sericicalyx & - & - & - & $\mathrm{x}$ & - & - & - & - & $\mathrm{x}$ \\
\hline Coutarea hexandra & $\mathrm{x}$ & $\mathrm{x}$ & - & - & - & $\mathrm{x}$ & - & - & - \\
\hline Croton floribundus & $\mathrm{x}$ & - & - & - & - & - & - & - & - \\
\hline Cupania sp. & $\mathrm{x}$ & - & $\mathrm{x}$ & $\mathrm{x}$ & $\mathrm{x}$ & - & - & - & - \\
\hline Cybistax antisyphilitica & & - & - & $\mathrm{x}$ & - & - & - & - & $\mathrm{x}$ \\
\hline Dalbergia nigra & - & - & $\mathrm{x}$ & - & - & - & $\mathrm{x}$ & $\mathrm{x}$ & - \\
\hline Dyctioloma vandellianum & $\mathrm{x}$ & - & $\mathrm{x}$ & - & - & - & $\mathrm{x}$ & - & $\mathrm{x}$ \\
\hline Endlicheria paniculata & - & - & - & - & - & - & - & - & $\mathrm{x}$ \\
\hline Eriotheca candolleana & $\mathrm{x}$ & - & - & - & - & - & - & - & $\mathrm{x}$ \\
\hline Erythrina sp. & - & - & - & - & - & - & $\mathrm{x}$ & - & - \\
\hline Erythroxylum pelleterianum & - & $\mathrm{x}$ & $\mathrm{x}$ & $\mathrm{x}$ & - & - & $\mathrm{x}$ & - & $\mathrm{x}$ \\
\hline Eugenia brasiliensis & - & - & - & - & $\mathrm{x}$ & $\mathrm{x}$ & - & - & - \\
\hline Eugenia cf. cerasiflora & - & - & $\mathrm{x}$ & $\mathrm{x}$ & $\mathrm{x}$ & $\mathrm{x}$ & - & $\mathrm{x}$ & - \\
\hline Eugenia leptoclada & - & - & - & $\mathrm{x}$ & - & - & - & - & - \\
\hline Euterpe edulis & - & - & - & - & $\mathrm{x}$ & $\mathrm{x}$ & - & - & - \\
\hline Ficus insipida & - & - & - & - & $\mathrm{x}$ & - & - & - & - \\
\hline Ficus mexiae & - & - & - & - & - & $\mathrm{x}$ & - & - & - \\
\hline Ficus sp. & - & - & - & - & - & & - & - & - \\
\hline Rheedia gardneriana & - & - & $\mathrm{x}$ & - & - & - & - & - & - \\
\hline Guapira opposita & - & - & $\mathrm{x}$ & $\mathrm{x}$ & $\mathrm{x}$ & $\mathrm{x}$ & - & - & $\mathrm{x}$ \\
\hline Guarea kunthia & - & - & - & - & 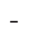 & - & - & $\mathrm{x}$ & - \\
\hline Guarea r & - & - & - & - & $\mathrm{x}$ & $\mathrm{x}$ & - & - & - \\
\hline Guarea guidonia & - & - & - & - & $\mathrm{x}$ & $\mathrm{x}$ & - & - & - \\
\hline Guatteria nigrescens & - & - & - & - & - & - & $\mathrm{x}$ & - & - \\
\hline Guettarda viburnoides & & & $\mathrm{x}$ & & $\mathrm{x}$ & $\mathrm{x}$ & $\mathrm{x}$ & & $\mathrm{x}$ \\
\hline a alchorneoides & - & - & - & - & $\mathrm{x}$ & $\mathrm{x}$ & - & - & - \\
\hline $\begin{array}{l}\text { Himatanthus } \\
\text { phagedaenicus }\end{array}$ & - & - & $\mathrm{x}$ & - & - & - & - & - & - \\
\hline Hirtella hebeclada & - & - & - & - & - & $\mathrm{X}$ & - & - & - \\
\hline Hortia arborea & $\mathrm{x}$ & - & $\mathrm{x}$ & $\mathrm{x}$ & - & - & - & - & - \\
\hline Hyptidendron asperrimum & - & - & - & - & - & - & $\mathrm{x}$ & - & - \\
\hline Inga edulis & - & - & - & - & - & $\mathrm{x}$ & $\mathrm{x}$ & - & $\mathrm{x}$ \\
\hline Inga marginata & - & - & $\mathrm{x}$ & - & - & - & - & - & - \\
\hline Inga sp. & - & - & $\mathrm{x}$ & - & - & - & - & - & - \\
\hline Jacaranda sp. & - & $\mathrm{x}$ & $\mathrm{x}$ & $\mathrm{x}$ & - & - & $\mathrm{x}$ & $\mathrm{x}$ & $\mathrm{x}$ \\
\hline pubescens & - & - & $\mathrm{x}$ & $\mathrm{x}$ & - & - & - & - & $\mathrm{x}$ \\
\hline Ladenbergia hexandra & - & - & $\mathrm{x}$ & $\mathrm{x}$ & - & - & - & - & $\mathrm{x}$ \\
\hline Lamanonia ternata & - & - & $\mathrm{x}$ & - & $\mathrm{x}$ & 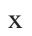 & - & - & $\mathrm{X}$ \\
\hline Lauraceae 1 & - & - & $\mathrm{x}$ & $\mathrm{x}$ & $\mathrm{x}$ & $x$ & $\mathrm{x}$ & - & $\mathrm{x}$ \\
\hline cho & - & - & - & - & - & - & $\mathrm{x}$ & - & - \\
\hline Luehea grandiflora & - & $\mathrm{x}$ & - & $\mathrm{x}$ & - & $\mathrm{x}$ & $\mathrm{x}$ & $\mathrm{x}$ & $\mathrm{x}$ \\
\hline Mabea fistulifera & - & - & - & - & - & - & - & - & $\mathrm{x}$ \\
\hline Machaerium $n$ & - & - & $\mathrm{x}$ & - & - & $\mathrm{x}$ & $\mathrm{x}$ & 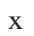 & $\mathrm{x}$ \\
\hline Machaerium stipitatu & - & - & - & - & - & - & - & $X$ & - \\
\hline Machaerium triste & - & - & - & - & - & - & - & - & $\mathrm{x}$ \\
\hline Maclura tinctoria & - & $\mathrm{x}$ & - & - & - & - & - & - & - \\
\hline Mapro & - & - & $\mathrm{x}$ & - & - & & - & - & - \\
\hline Matayba elaeagnoides & - & - & $\mathrm{x}$ & - & - & $x$ & - & $\mathrm{x}$ & $\mathrm{x}$ \\
\hline Matayba jugandifolia & - & - & $\mathrm{x}$ & - & - & - & - & - & - \\
\hline Miconia albo-r & - & - & - & $\mathrm{x}$ & - & - & - & - & - \\
\hline Miconia cinn & $\mathrm{x}$ & $\mathrm{x}$ & - & - & - & - & $\mathrm{x}$ & $\mathrm{x}$ & - \\
\hline Miconia pusilliflora & - & - & - & - & $\mathrm{x}$ & $\mathrm{x}$ & - & - & - \\
\hline Miconia sp. & - & - & - & - & - & - & - & $\mathrm{x}$ & - \\
\hline Myrcia fallax & $\mathrm{x}$ & $\mathrm{x}$ & $\mathrm{x}$ & $\mathrm{x}$ & - & - & - & $\mathrm{x}$ & $\mathrm{x}$ \\
\hline Myrcia sp. & $\mathrm{x}$ & - & $\mathrm{x}$ & - & $\mathrm{x}$ & $\mathrm{x}$ & - & $\mathrm{x}$ & $\mathrm{x}$ \\
\hline Myrciaria sp. & - & - & - & - & $\mathrm{x}$ & $\mathrm{x}$ & - & - & - \\
\hline Myrtaceae 1 & - & - & - & $\mathrm{x}$ & - & - & - & - & - \\
\hline Nectandra reticulata & - & - & - & $\mathrm{x}$ & - & - & - & - & - \\
\hline Nectandra rigida & $\mathrm{x}$ & $\mathrm{x}$ & $\mathrm{x}$ & $\mathrm{x}$ & $\mathrm{x}$ & $\mathrm{x}$ & $\mathrm{x}$ & $\mathrm{x}$ & $\mathrm{x}$ \\
\hline
\end{tabular}

Continua.. Continued..
Quadro 3, cont.

Table 3, cont.

\begin{tabular}{|c|c|c|c|c|c|c|c|c|c|}
\hline \multirow[t]{2}{*}{ Espécies } & \multicolumn{9}{|c|}{ Local } \\
\hline & 1 & 2 & 3 & 4 & 5 & 6 & 8 & 9 & 10 \\
\hline Nectandra saligna & $\mathrm{x}$ & $\mathrm{x}$ & - & - & $\mathrm{x}$ & $\mathrm{x}$ & - & $\mathrm{x}$ & - \\
\hline Ocotea corymbosa & - & $\mathrm{x}$ & - & - & $\mathrm{x}$ & $\mathrm{x}$ & $\mathrm{x}$ & - & $\mathrm{x}$ \\
\hline Ocotea laxa & - & - & - & - & $\mathrm{x}$ & $\mathrm{x}$ & - & - & - \\
\hline Ocotea odorifera & - & - & - & $\mathrm{x}$ & - & - & - & - & $\mathrm{x}$ \\
\hline Ocotea pubescens & - & - & - & - & - & $\mathrm{x}$ & - & - & - \\
\hline Ouratea polygyna & - & $\mathrm{x}$ & - & - & - & $\mathrm{x}$ & - & - & - \\
\hline Peschiera fuchsiaefolia & - & $\mathrm{x}$ & $\mathrm{x}$ & - & - & $\mathrm{x}$ & $\mathrm{x}$ & - & - \\
\hline $\begin{array}{l}\text { Phyllostemonodaphne } \\
\text { geminiflora }\end{array}$ & - & - & - & $\mathrm{x}$ & - & $\mathrm{x}$ & - & $\mathrm{x}$ & - \\
\hline Picramnia glazioviana & - & - & - & - & $\mathrm{x}$ & - & - & - & - \\
\hline Picramnia regnelli & - & - & - & - & - & $\mathrm{x}$ & - & - & - \\
\hline Piptadenia gonoacantha & $\mathrm{x}$ & $\mathrm{x}$ & $\mathrm{x}$ & - & $\mathrm{x}$ & $\mathrm{x}$ & $\mathrm{x}$ & $\mathrm{x}$ & $\mathrm{x}$ \\
\hline Piptocarpha macropoda & $\mathrm{x}$ & $\mathrm{x}$ & - & - & $\mathrm{x}$ & - & $\mathrm{x}$ & $\mathrm{x}$ & - \\
\hline Platymiscium pubescens & - & $\mathrm{x}$ & - & - & - & - & - & - & - \\
\hline Pouteria sp. & - & - & - & $\mathrm{x}$ & - & - & - & - & - \\
\hline Protium warmingianum & - & - & $\mathrm{x}$ & $\mathrm{x}$ & $\mathrm{x}$ & $\mathrm{x}$ & - & - & - \\
\hline Prunus sellowii & - & $\mathrm{x}$ & - & - & $\mathrm{x}$ & - & $\mathrm{x}$ & $\mathrm{x}$ & - \\
\hline $\begin{array}{l}\text { Pseudobombax } \\
\text { longiflorum }\end{array}$ & - & - & - & - & $\mathrm{x}$ & $\mathrm{x}$ & - & - & - \\
\hline seudopiptadenia contorta & $a-$ & $\mathrm{x}$ & - & $\mathrm{x}$ & - & - & - & - & - \\
\hline Psidium guajava & - & - & $\mathrm{x}$ & $\mathrm{x}$ & - & - & - & - & - \\
\hline Psychotria sessilis & - & - & - & - & - & - & - & $\mathrm{x}$ & - \\
\hline Randia armata & - & $\mathrm{x}$ & - & - & - & $\mathrm{x}$ & - & - & - \\
\hline Rapanea ferrugine & - & - & - & - & - & - & - & $\mathrm{x}$ & - \\
\hline Rollinia silvatica & $\mathrm{x}$ & - & $\mathrm{x}$ & - & $\mathrm{x}$ & $\mathrm{x}$ & $\mathrm{x}$ & $\mathrm{x}$ & $\mathrm{x}$ \\
\hline Sapium glandulatum & $\mathrm{x}$ & $\mathrm{x}$ & - & - & $\mathrm{x}$ & - & $\mathrm{x}$ & - & - \\
\hline Didymopanax morototon & $i-$ & - & - & - & - & - & $\mathrm{x}$ & - & $\mathrm{x}$ \\
\hline Sclerolobium denudatum & - & - & $\mathrm{x}$ & - & - & - & $\mathrm{x}$ & - & - \\
\hline Senna macranthera & $\mathrm{x}$ & $\mathrm{x}$ & - & - & - & - & - & $\mathrm{x}$ & - \\
\hline Senna multijuga & $\mathrm{x}$ & - & - & - & - & $\mathrm{x}$ & $\mathrm{x}$ & $\mathrm{x}$ & $\mathrm{x}$ \\
\hline Siparuna arianeae & - & - & - & $\mathrm{x}$ & - & - & $\mathrm{x}$ & $\mathrm{x}$ & - \\
\hline Siparuna guianensis & $\mathrm{x}$ & $\mathrm{x}$ & $\mathrm{x}$ & $\mathrm{x}$ & $\mathrm{x}$ & $\mathrm{x}$ & $\mathrm{x}$ & $\mathrm{x}$ & $\mathrm{x}$ \\
\hline Solanum argenteum & - & - & - & - & - & - & - & $\mathrm{x}$ & - \\
\hline Solanum cernuum & - & - & - & - & - & - & - & $\mathrm{x}$ & - \\
\hline Solanum leucodendron & - & $\mathrm{x}$ & $\mathrm{x}$ & - & - & - & $\mathrm{x}$ & - & - \\
\hline Solanum sp.1 & - & - & - & - & - & - & - & $\mathrm{x}$ & - \\
\hline Sorocea bonplandii & - & - & $\mathrm{x}$ & $\mathrm{x}$ & $\mathrm{x}$ & $\mathrm{x}$ & - & - & $\mathrm{x}$ \\
\hline $\begin{array}{l}\text { Sparattosperma } \\
\text { leucanthum }\end{array}$ & $\mathrm{x}$ & $\mathrm{x}$ & - & - & - & $\mathrm{x}$ & $\mathrm{x}$ & $\mathrm{x}$ & $\mathrm{x}$ \\
\hline $\begin{array}{l}\text { Stryphnodendron } \\
\text { guianense }\end{array}$ & - & - & - & - & - & - & - & - & $\mathrm{x}$ \\
\hline Swartzia myrtifolia & - & - & $\mathrm{x}$ & - & - & - & - & - & - \\
\hline Syagrus romanzoffic & - & - & $\mathrm{x}$ & - & - & - & - & - & $\mathrm{x}$ \\
\hline Tabebuia chrysotricha & - & - & - & - & - & - & $\mathrm{x}$ & - & - \\
\hline Tapirira guianensis & - & - & - & - & $\mathrm{x}$ & - & - & - & - \\
\hline Terminalia sp. & - & - & - & $\mathrm{x}$ & - & - & - & - & - \\
\hline Tibouchina granulosc & - & $\mathrm{x}$ & - & - & - & - & - & - & - \\
\hline nickia ferruginea & - & - & - & $\mathrm{x}$ & $\mathrm{x}$ & - & - & - & - \\
\hline Trema micrantha & - & - & - & - & - & - & - & $\mathrm{x}$ & - \\
\hline Trichilia catigua & - & - & $\mathrm{x}$ & $\mathrm{x}$ & $\mathrm{x}$ & - & $\mathrm{x}$ & - & - \\
\hline Trichilia lepi & - & - & - & - & - & $\mathrm{x}$ & $\mathrm{x}$ & - & - \\
\hline Trichilia pallida & - & - & - & - & - & - & - & $\mathrm{x}$ & - \\
\hline Vernonia diffusa & $\mathrm{x}$ & $\mathrm{x}$ & - & - & - & $\mathrm{x}$ & $\mathrm{x}$ & $\mathrm{x}$ & $\mathrm{x}$ \\
\hline Villaresia megaphylla & - & - & - & $\mathrm{x}$ & $\mathrm{x}$ & - & - & - & - \\
\hline Virola oleifera & - & - & $\mathrm{x}$ & - & $\mathrm{x}$ & $\mathrm{x}$ & $\mathrm{x}$ & $\mathrm{x}$ & - \\
\hline Vismia guianensis & $\mathrm{x}$ & $\mathrm{x}$ & - & - & - & - & $\mathrm{x}$ & $\mathrm{x}$ & $\mathrm{x}$ \\
\hline Vitex sellowiana & $\mathrm{x}$ & - & - & $\mathrm{x}$ & - & - & $\mathrm{x}$ & - & $\mathrm{x}$ \\
\hline Xylopia brasiliensis & - & - & - & - & - & $\mathrm{x}$ & - & - & - \\
\hline Xylopia sericea & $\mathrm{x}$ & - & - & $\mathrm{x}$ & - & - & $\mathrm{x}$ & $\mathrm{x}$ & $\mathrm{x}$ \\
\hline Xylosma prockia & - & - & - & 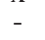 & $\mathrm{x}$ & $\mathrm{x}$ & - & - & - \\
\hline Zanthoxylum rhoifolium & $\mathrm{x}$ & $\mathrm{x}$ & $\mathrm{x}$ & & $\mathrm{x}$ & & $\mathrm{x}$ & $\mathrm{x}$ & \\
\hline Zeyheria tuberculosa & $\mathrm{x}$ & - & - & - & - & - & - & - & - \\
\hline Total & 147 & 221 & 246 & 177 & 243 & 294 & 233 & & 210 \\
\hline
\end{tabular}


O grupo ecológico que mais se destacou no período de nove anos de estudo, no fragmento como um todo, foi o das secundárias iniciais, representado por 97 espécies e 1.678 indivíduos, seguido de secundárias tardias (40 espécies e 331 indivíduos) e pioneiras (24 espécies e 298 indivíduos). Em 1992, o grupo das secundárias iniciais apresentou 90 espécies e 1.378 indivíduos (62 e $71 \%$ do total); das secundárias tardias, 35 espécies e 293 indivíduos (24 e 15\% do total); e o das pioneiras, 21 espécies e 279 indivíduos (14\% do total). Em 2001, as espécies secundárias iniciais representaram $60 \%$ do total (90 espécies), as tardias 25\% (38 espécies) e as pioneiras 15\% (22 espécies), e o número de indivíduos correspondeu a 75 (1.485), 13 (260) e 12\% (227 indivíduos) do total, nos três grupos ecológicos, respectivamente.

O percentual de espécies permaneceu estável, e o número de indivíduos das espécies secundárias iniciais aumentou no período de nove anos, o grupo das secundárias tardias apresentou aumento de espécies, o grupo das pioneiras teve redução no seu valor percentual de indivíduos e o número de espécies aumentou muito pouco, o que demonstra que a floresta está evoluindo em relação ao estádio sucessional. Segundo a classificação da Resolução do CONAMA 010/1993, esse remanescente florestal pode ser considerado uma floresta secundária em estádio médio de regeneração, pois os estratos arbóreo e arbustivo predominam sobre o estrato herbáceo, podendo apresentar estratos diferenciados; o dossel varia de aberto a fechado, com a ocorrência eventual de indivíduos emergentes. É também característica, nesse estádio, a presença de sub-bosque, manta orgânica e predomínio de trepadeiras lenhosas. Segundo Pezzopane (2001), o índice de área foliar médio dessa floresta é de 4,5, e a transmissividade da RFA (radiação fotossinteticamente ativa) nos 10 locais variou de 2,5 a 9,3\%, sendo a média do fragmento de $4,1 \%$.

Comparando os índices de diversidade no período de 1992 a 2001 (Quadro 4) de alguns locais, não houve diferença significativa de diversidade ao longo de nove anos de estudo. Nos locais 1, 2 e 9 amostrados nesta pesquisa (Figura 1 ), verificou-se acréscimo significativo no índice de diversidade ( $\left.\mathrm{H}^{\prime}\right)$, tendo sido, também, as áreas com os menores valores médios de H' $(2,57$; 2,59; e 2,61, respectivamente). Esses resultados podem ser explicados devido ao fato de tais locais apresentarem históricos de perturbação semelhantes, sendo reflexo do intenso grau de intervenção antrópica numa curta variação espacial, conforme discutido por Almeida Júnior (1999). Os locais 1, 2 e 9 tiveram maior incremento percentual no número de indivíduos arbóreos em relação às outras áreas de estudo (71, 57 e 37\%, respectivamente). De acordo com Fernandes (1998), locais em estádios iniciais de sucessão apresentam maior aumento no número de indivíduos (ingressos). Nesses locais são encontradas maiores quantidades de lianas, que são heliófitas e ocorrem, principalmente, em ambientes submetidos a fortes perturbações antrópicas.

Quadro 4 - Número de indivíduos (N), família (F), espécie (Sp) e índice de diversidade de Shannon-Weaver (H') nos 10 locais, nos anos de 1992, 1995, 1998 e 2001, em uma floresta secundária, na Estação de Pesquisa, Treinamento e Educação Ambiental, no Município de Viçosa, Minas Gerais

Table 4 - Number of individuals ( $N$ ), families ( F) and species (Sp), and the Shannon-Weaver diversity index ( $H^{\prime}$ ) of adult trees sampled in 10 sites in 1992, 1995, 1998 and 2001, in a secondary semi-deciduous seasonal forest fragment, domain of the Atlantic Forest, in Viçosa, MG, Brazil

\begin{tabular}{|c|c|c|c|c|c|c|c|c|c|c|c|c|c|c|c|c|}
\hline \multirow[b]{2}{*}{ Local } & \multicolumn{4}{|c|}{1992} & \multicolumn{4}{|c|}{1995} & \multicolumn{4}{|c|}{1998} & \multicolumn{4}{|c|}{2001} \\
\hline & $\mathrm{N}$ & $\mathrm{F}$ & Sp & $\mathrm{H}^{\prime}$ & $\mathrm{N}$ & $\mathrm{F}$ & Sp & $\mathrm{H}^{\prime}$ & $\mathrm{N}$ & $F$ & Sp & $\mathrm{H}^{\prime}$ & $\mathrm{N}$ & $\mathrm{F}$ & $\mathrm{Sp}$ & $\overline{\mathrm{H}^{\prime}}$ \\
\hline 1 & 86 & 14 & 19 & $2,43^{a}$ & 120 & 17 & 26 & $2,65^{\mathrm{ab}}$ & 134 & 16 & 26 & $2,68^{\mathrm{b}}$ & 147 & 17 & 27 & $2,68^{\mathrm{b}}$ \\
\hline 2 & 161 & 19 & 28 & $2,44^{\mathrm{a}}$ & 222 & 23 & 34 & $2,57^{a}$ & 229 & 24 & 35 & $2,65^{b}$ & 221 & 24 & 34 & $2,68^{\mathrm{b}}$ \\
\hline 3 & 259 & 29 & 55 & $3,36^{a}$ & 259 & 29 & 55 & $3,35^{\mathrm{a}}$ & 253 & 29 & 52 & $3,28^{\mathrm{a}}$ & 246 & 28 & 51 & $3,25^{\mathrm{a}}$ \\
\hline 4 & 194 & 27 & 52 & $3,43^{a}$ & 193 & 29 & 51 & $3,35^{a}$ & 185 & 26 & 47 & $3,25^{b}$ & 177 & 26 & 45 & $3,16^{b}$ \\
\hline 5 & 267 & 26 & 49 & $3,26^{a}$ & 263 & 27 & 49 & $3,27^{\mathrm{a}}$ & 259 & 27 & 51 & $3,22^{\mathrm{a}}$ & 243 & 27 & 49 & $3,22^{a}$ \\
\hline 6 & 289 & 27 & 59 & $3,31^{\mathrm{a}}$ & 295 & 27 & 59 & $3,31^{\mathrm{a}}$ & 302 & 29 & 58 & $3,33^{a}$ & 294 & 29 & 58 & $3,33^{a}$ \\
\hline 7 & 179 & 29 & 56 & $3,61^{\mathrm{a}}$ & 205 & 31 & 60 & $3,65^{a}$ & 211 & 31 & 58 & $3,61^{\mathrm{a}}$ & 204 & 30 & 57 & $3,59^{\mathrm{a}}$ \\
\hline 8 & 177 & 25 & 41 & $3,26^{a}$ & 225 & 27 & 47 & $3,42^{\mathrm{b}}$ & 240 & 27 & 48 & $3,44^{\mathrm{b}}$ & 233 & 27 & 47 & $3,40^{\mathrm{ab}}$ \\
\hline 9 & 128 & 26 & 31 & $2,26^{a}$ & 204 & 33 & 39 & $2,53^{\mathrm{ab}}$ & 204 & 30 & 41 & $2,67^{\mathrm{bc}}$ & 201 & 33 & 44 & $2,82^{\mathrm{c}}$ \\
\hline 10 & 209 & 30 & 45 & $3,08^{\mathrm{a}}$ & 227 & 31 & 52 & $3,17^{a}$ & 214 & 30 & 52 & $3,17^{a}$ & 211 & 29 & 50 & $3,14^{\mathrm{a}}$ \\
\hline Total & 1949 & 45 & 146 & $4,26^{\mathrm{a}}$ & 2212 & 47 & 154 & $4,20^{\mathrm{a}}$ & 2231 & 48 & 157 & $4,23^{a}$ & 1972 & 46 & 150 & $4,22^{\mathrm{a}}$ \\
\hline
\end{tabular}

Nota: valores seguidos de letras iguais na horizontal indicam que o índice de diversidade não apresenta diferença significativa pelo teste $\mathrm{t}(\mathrm{P}<0,05)$. 
A floresta como um todo apresentou índices de diversidade, nos anos de 1992, 1995, 1998 e 2001, de 4,26; 4,20; 4,23; e 4,22, respectivamente, obtendo um valor médio de 4,22. Esses valores de diversidade não são significativamente diferentes (Quadro 4), indicando não ter havido, no período de nove anos, intervenção antrópica ou natural, que comprometesse a diversidade desse fragmento florestal. Conforme Meira Neto e Martins (2000), têm sido encontrados índices de diversidade em florestas Estacionais Semideciduais no Estado de Minas Gerais variando, geralmente, entre 3,2 e 4,2. O índice de diversidade verificado no presente trabalho é, também, superior aos obtidos em outros fragmentos na região de Viçosa, conforme registrado no estudo de Louzada (2002), sobre um fragmento de floresta Estacional Semidecidual Montana, no Município de Paula Cândido, Minas Gerais, em que H' variou de 3,22 a 3,71, em diferentes exposições do terreno. Campos (2002) resgistrou H’ de 3,52 em uma ravina de Floresta Estacional Semidecidual Montana, em Minas Gerais. Outros autores encontraram, em Viçosa, valores de índice de diversidade (H') acima de 4 (MARANGON, 1999; MEIRANETO e MARTINS, 2000). É possível que o valor elevado de H', obtido por Meira Neto e Martins (2000), se deva ao CAP mínimo adotado ( $\geq 10 \mathrm{~cm})$, permitindo a inclusão de maior número de espécies de sub-bosque, com altas densidades. O índice de diversidade elevado observado no trabalho de Marangon (1999), em que se usou o nível de inclusão de $5 \mathrm{~cm}$ de DAP para vegetação adulta, e o encontrado neste trabalho durante o período de nove anos, pode ser devido ao fato de a amostragem cobrir áreas bastante heterogêneas, no que se refere a solo, microclima, exposição, declividade e outros. Para Silva et al. (2000), a comparação entre índices de diversidade demanda cautela, uma vez que vários fatores relacionados à sucessão da vegetação e ao método de amostragem podem interferir nos valores, a exemplo do tamanho da parcela e do critério de inclusão adotados.

\section{CONCLUSÕES}

Considerando os resultados obtidos, pode-se concluir que:

- As famílias Leguminosae, Lauraceae, Euphorbiaceae, Myrtaceae, Flacourtiaceae e Meliaceae são as mais importantes nessa floresta, merecendo destaque a familía Leguminosae, por ter a maior riqueza de espécies possivelmente em razão, da estratégia de vida de suas espécies, caracterizada pela capacidade de associação simbiótica com bactérias fixadoras de nitrogênio atmosférico.

- As espécies Ficus insipida, Ficus mexiae e Xylopia brasiliensis, devido ao fato de possuírem apenas um indivíduo amostrado no intervalo de nove anos e não apresentarem regeneração natural, devem ser manejadas com técnicas que possam ajudar no aumento de suas populações, a exemplo do plantio de enriquecimento, mantendo, dessa forma, a diversidade biológica da floresta.

- A floresta secundária entre o período de 1992 e 2001 teve avanço no seu estádio sucessional, o que pode ser caracterizado pela redução, tanto de espécies quanto de indíviduos arbóreos do grupo de espécies pioneiras, e pelo favorecimento para o estabelecimento de espécies que ocorrem em estádios sucessionais avançados.

- Locais com histórico de perturbação semelhantes que foram submetidos a intensa intervenção antrópica apresentaram baixa diversidade, podendo representar, no mosaico florestal, áreas em estádios mais iniciais de sucessão.

- Em conjunto, esses resultados indicam que o fragmento estudado se encontra em estádio intermediário de sucessão.

\section{REFERÊNCIAS BIBLIOGRÁFICAS}

\section{ALMEIDA JÚNIOR, J.S. Florística e} fitossociologia de fragmentos da floresta estacional semidecidual, Viçosa, MG. 1999. 148f. Dissertação (Mestrado em Ciência Florestal) - Universidade Federal de Viçosa, Viçosa, 1999.

\section{CAMPOS, E.P. Florística e estrutura horizontal da vegetação arbórea de uma ravina em um fragmento florestal no Município de Viçosa - MG. 2002. 61f. Dissertação (Mestrado em Botânica) - Universidade Federal de Viçosa, Viçosa, 2002.}

CONAMA.- Conselho Nacional do Meio Ambiente. Resolução $n^{\circ}$ 010/93.

CRONQUIST, A. The evolution and classification of flowering plants. New York: The New York Botanical Garden, 1988. 555 p.

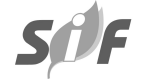

R. Árvore, Viçosa-MG, v.28, n.3, p. 429-441, 2004 
FERNANDES, H.A.C. Dinâmica e distribuição de espécies arbóreas em uma floresta secundária no domínio da Mata Atlântica. 1998. 148f. Dissertação (Mestrado em Ciência Florestal) - Universidade Federal de Viçosa, Viçosa, 1998.

HIGUCHI, P. Dinâmica da regeneração natural da vegetação arbórea em um fragmento de floresta estacional semidecidual secundária, em Viçosa, MG. 2003. 137f. Dissertação (Mestrado em Ciência Florestal) - Universidade Federal de Viçosa, Viçosa, 2003.

INDEX KEWENSIS. Disponível em: < http:// www.ipni.org/ipni/query_ipni.html>. Acesso em: 11/nov/2002.

LEAL FILHO, N. Caracterização do banco de sementes de três estádios de uma sucessão vegetal na Zona da Mata de Minas Gerais. 1992. 116f. Dissertação (Mestrado em Ciência Florestal) - Universidade Federal de Viçosa, Viçosa, 1992.

LEITÃO FILHO, H.F. Considerações sobre a florística de florestas tropicais e subtropicais do Brasil. Revista IPEF, v. 35, p. 41-46, 1987.

LOPEZ, W.P. et al. Composição da flora arbórea de um trecho de floresta estacional no jardim botânico da Universidade Federal de Viçosa (face sudoeste), Viçosa, Minas Gerais. Revista Árvore, v. 26, n. 3, p. 339- 347, 2002.

LOUZADA, C. Composição florística e estrutura de vegetação arbórea em diferentes condições fisiográficas de um fragmento de floresta estacional semidecidual secundária, na Zona da Mata de Minas Gerais. 2002. 149f. Dissertação (Mestrado em Ciência Florestal) Universidade Federal de Viçosa, Viçosa, 2002.

MARANGON, L.C. Florística e fitossociologia de área de floresta estacional semidecidual visando dinâmica de espécies florestais arbóreas no Município de Viçosa MG. 1999. 145f. Tese (Doutorado em Ecologia e Recursos Naturais) - Universidade Federal de São Carlos, São Carlos, 1999.

R. Árvore, Viçosa-MG, v.28, n.3, p. 429-441, 2004
MARANGON, L.C.; SOARES, J.J.; FELICIANO, A.L.P. Florística arbórea da mata da pedreira, município de Viçosa, Minas Gerais. Revista Árvore, v. 27, n. 2, p. 207- 215, 2003.

MARTINS, F.R. O método de quadrantes e a fitossociologia de uma floresta residual do interior do estado de São Paulo: Parque Estadual de Vassununga. 1979. 239f. Tese (Doutorado em Ciências) - Universidade de São Paulo, São Paulo, 1979.

MEIRA NETO, J.A.A.; MARTINS, F.R. Estrutura da mata da silvicultura, uma floresta estacional semidecidual montana no Munícipio de Viçosa MG. Revista Árvore, v. 24, n. 2, p. 151- 160, 2000.

PAULA, A.; SILVA, A.F.; SOUZA, A.L. Alterações florísticas ocorridas num período de quartoze anos na vegetação arbórea de uma floresta estacional semidecidual em Viçosa-MG. Revista Árvore, v. 26, n. 6, p. 743-749, 2002.

PEREIRA, R.A. Mapeamento e caracterização de fragmentos de vegetação arbórea e alocação de áreas preferenciais para sua interligação no município de Viçosa, MG. 1999. 250f. Tese (Doutorado em Ciência Florestal) - Universidade Federal de Viçosa, Viçosa, 1999.

PEZZOPANE, J.E.M. Caracterização fitossociológica, microclimática e ecofisiológica em uma floresta estacional semidecidual secundária. Viçosa, 2001. 225f. Tese (Doutorado em Ciência Florestal) - Universidade Federal de Viçosa, Viçosa, 2001.

SILVA, A.F.; FONTES, N.R.; LEITÃO FILHO, H. Composição florística e estrutura horizontal do estrato arbóreo de um trecho da mata da biologia da Universidade Federal de Viçosa - Zona da Mata de Minas Gerais. Revista Árvore, v. 24, n. 4, p. 397-405, 2000.

SILVA, N.R.S. Florística e estrutura horizontal de uma floresta estacional semidecidual Montana - Mata do Juquinha de Paula, Viçosa, MG. Viçosa, 2002. 68f. Dissertação (Mestrado em Ciência Florestal) - Universidade Federal de Viçosa, Viçosa, 2002. 
SOUZA, A.L. et al. Dinâmica da composição florística de uma floresta ombrófila densa secundária, após corte de cipós, reserva natural da Companhia Vale do Rio Doce S.A., Estado do Espírito Santo, Brasil. Revista Árvore, v. 26, n. 5, p. 549-558, 2002.

VELOSO, H.P.; RANGEL FILHO, A.L.R.; LIMA, J.C.A. Classificação da vegetação brasileira, adaptada a um sistema universal. Rio de Janeiro: IBGE, 1991. 123 p.
VIANELLO, R.L.; ALVES, A.R. Meteorologia básica e aplicações. Viçosa: UFV, 1991. 449 p.

VIDAL, E.; VIANA, V.; BATISTA, J.L.F. Efeito da exploração madeireira predatória e planejada sobre a diversidade de espécies na amazônia oriental. Revista Árvore, v. 22, n. 4, p. 503-520, 1998.

VOLPATO, M.M.L. Regeneração natural em uma floresta secundária no domínio de Mata Atlântica: uma análise fitossociológica. 1994. 123f. Dissertação

(Mestrado em Ciência Florestal) - Universidade Federal de Viçosa, Viçosa, 1994. 